\title{
Autologous mitochondrial microinjection; a strategy to improve the oocyte quality and subsequent reproductive outcome during aging
}

\author{
Halimeh Mobarak ${ }^{1,2}$, Mohammad Heidarpour ${ }^{2}$, Pei-Shiue Jason Tsai ${ }^{3,4}$, Aysa Rezabakhsh ${ }^{5}$, Reza Rahbarghazi ${ }^{6,7}$, \\ Mohammad Nouri, ${ }^{6,8}$ and Mahdi Mahdipour ${ }^{6,8^{*}}$ (D)
}

\begin{abstract}
Along with the decline in oocyte quality, numerous defects such as mitochondrial insufficiency and the increase of mutation and deletion have been reported in oocyte mitochondrial DNA (mtDNA) following aging. Any impairments in oocyte mitochondrial function have negative effects on the reproduction and pregnancy outcome. It has been stated that infertility problems caused by poor quality oocytes in women with in vitro fertilization (IVF) and repeated pregnancy failures are associated with aging and could be overcome by transferring large amounts of healthy mitochondria. Hence, researches on biology, disease, and the therapeutic use of mitochondria continue to introduce some clinical approaches such as autologous mitochondrial transfer techniques. Following mitochondrial transfer, the amount of ATP required for aged-oocyte during fertilization, blastocyst formation, and subsequent embryonic development could be an alternative modality. These modulations improve the pregnancy outcome in women of high reproductive aging as well. In addition to overview the clinical studies using mitochondrial microinjection, this study provides a framework for future approaches to develop effective treatments and preventions of congenital transmission of mitochondrial DNA mutations/diseases to offspring. Mitochondrial transfer from ovarian cells and healthy oocytes could lead to improved fertility outcome in low-quality oocytes. The modulation of mitochondrial bioactivity seems to regulate basal metabolism inside target oocytes and thereby potentiate physiological activity of these cells while overcoming age-related infertility in female germ cells.
\end{abstract}

Keywords: Oocyte quality, Mitochondrial transfer, Ageing, Reproduction

\section{Background}

Aging is known to cause complications and time-dependent pathologies in cellular functions which affects most living organisms. The underlying cause of aging is still not fully understood; however, the most prominent theory is a mitochondrial free radical theory of aging (MFRTA) [1-3]. Based on this theory, reactive oxygen species (ROS), and diverse toxic byproducts are produced during aerobic metabolisms which are likely involved in cellular

\footnotetext{
*Correspondence: mahdipourm@tbzmed.ac.ir

${ }^{6}$ Stem Cell Research Center, Tabriz University of Medical Sciences, Tabriz, Iran

Full list of author information is available at the end of the article
}

genomes and mitochondrial DNA (mtDNA) injury and mutations. The increased production of ROS causes distinct impairment in the cellular respiratory chain leading to mutation accumulation and imbalanced redox activity $[1,4,5]$. The basal levels of ROS are often declined during the normal functioning phase of the mitochondrial respiratory chain, whereas the surplus amount of cellular ROS is seen by aging, contributing to the significant increase in oxidative damage and the loss of cellular activity $[4,5]$.

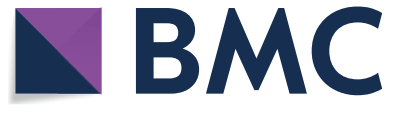

(c) The Author(s) 2019. This article is distributed under the terms of the Creative Commons Attribution 4.0 International License (http://creativecommons.org/licenses/by/4.0/), which permits unrestricted use, distribution, and reproduction in any medium, provided you give appropriate credit to the original author(s) and the source, provide a link to the Creative Commons license, and indicate if changes were made. The Creative Commons Public Domain Dedication waiver (http://creativecommons.org/ publicdomain/zero/1.0/) applies to the data made available in this article, unless otherwise stated. 


\section{Aging and mitochondria}

One of the most important cellular organelles affected upon aging is mitochondria. The vital function of energy (adenosine 5-triphosphate, ATP) production of mitochondria through oxidative phosphorylation makes it the powerhouse in each cells [6-8]. While mitochondria have been described to take part in the energy metabolism, homeostasis of calcium, growth, and cell apoptosis [9-11], they are also touted as the primary source of intracellular ROS production $[6,12]$.

Unlike other intracellular organelles, mitochondria have a unique genome known as mtDNA, a doublestranded and circular DNA with approximately $16.5 \mathrm{~kb}$ [13]. Due to the lack of genomic repair mechanisms and protective mechanisms of histones structure, the mutation rate of mtDNA is approximately 15 times higher when compared to nuclear genome mutation rate [14, 15]. It has been shown that the elevation of mtDNA somatic mutations per se can be induced by age-related ROS and free radicals accumulation resulting in mitochondrial dysfunction [12, 16]. Mammalian mitochondria are naturally inherited maternally, as the sperm mitochondria are degraded following fertilization in the oocyte in order to protect the embryo and offspring from possible transmission of mutations and heteroplasmy [17, 18]. Although the level of mtDNA heteroplasmic inheritance is low (1-2\%) in humans, it has been indicated that this low-level heteroplasmy inheritance along with other inherited mitochondrial and somatic mutations could contribute to the aging-related pathologies [19, 20].

\section{Relationship between mitochondria and oocyte aging}

The major population consulting fertility and assisted reproductive centers are often women of high reproductive age [12]. A decrement in both the quality and the number of oocytes is often associated with advanced maternal reproductive aging and the main reasons for the suboptimal reproductive outcome [12, 21-23]. Either cytoplasmic or nuclear oocyte maturation is essential for successful fertilization and embryonic development [23, 24]. The maturity of oocyte nucleus is characterized by the appearance of the polar body as a result of metaphase II in meiosis division, whereas the evaluation of mitochondrial parameters (such as distribution pattern and activity) is applied to assess the cytoplasmic maturity [24]. Upon aging, the decline in oocyte quality, defects in mitochondrial function as well as the increased level of mutation and deletion in oocyte mtDNA have been reported [25-27]. It has been shown that fertilization potency of the oocytes and subsequent growth potential of the embryos are integral to the number of mtDNA and
mtDNA content in elderly women which closely correlate with the production of ATP in developing embryos $[12,21,28-30]$. Due to the higher energy requirements in developing embryos, the reduction of glycolysis and preservation of mtDNA function until blastocyst stage in the oocytes are considered as the major source for supplying the required ATP during the oocyte maturation, cleavage, embryo preimplantation and embryogenesis $[6,17,31]$. It has been demonstrated that defects in mitochondrial biogenesis and ATP production system are associated with meiotic abnormalities, chromosomal aneuploidy, developmental arrest, follicular atresia, and eventually abnormal embryo development [17, 21, 26, 32]. Evidence from animal models showed that increased maternal age declined energy production efficiency in the oocytes which is highly correlated with the accumulation of mitochondrial genome mutations, morphological changes, increasing ROS production and interruption of the respiratory chain $[6,17,27,29]$. Therefore, the quality and quantity of mitochondria in the oocytes are important and could be essential indicators for successful fertilization and embryo growth [31,33].

Mitochondria proliferation is initiated in primordial germ cells (PGCs) after migration to ovary niche for the initiation of oogenesis and the number of mitochondria continues to increase during early and later stages of oogenesis process increasing from $200 \mathrm{mtDNA}$ copy number to over 200,000 copies. Therefore, the mature oocyte carries the most mtDNA copies compared to PGCs and immature oocytes [18]. However, owing to the lack of replication after maturation, a decline in intracellular mitochondrial numbers is observed in fertilized oocytes and blastocyst stage of preimplantation embryos. Nevertheless, the mitochondrial replication is resumed after the implantation stage [32]. The microscopic examination of mitochondria distribution and structure in human oocytes during oogenesis and embryogenesis confirmed that the mitochondria in the metaphase I (MI), metaphase II (MII) and fertilized oocytes in cleavage stage have inert appearance with round shape, dense matrix, transverse cristae and are spread throughout ooplasm with close association with smooth endoplasmic reticulum, whereas mitochondria in the morula and blastocysts stages are oval to spherical in shape and tend to be localized around nuclei, indicating the high mitochondrial dynamic, either in number and structure, during embryonic development [34]. The most morphological changes occur at blastocyst stage coincided with mitochondria elongation and development of transverse cristae, indicating that mitochondria are highly active during blastocyst expansion, differentiation and hatching. Significant changes in the mitochondrial distribution also occur in the pronuclear stage post-fertilization [34]. 


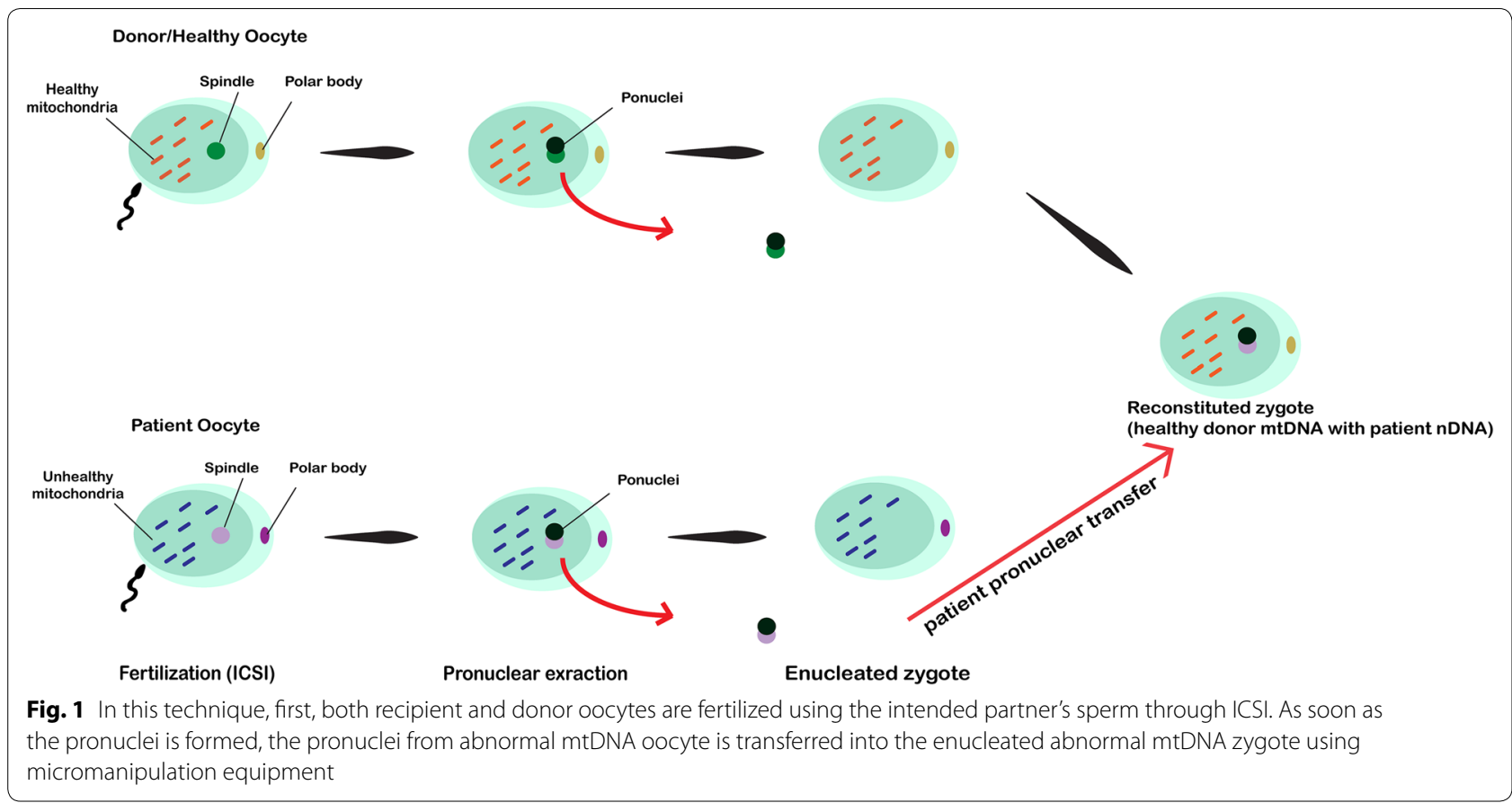

To date, various compounds, including antioxidants and coenzymes (e.g., L-carnitine [35], coenzyme Q10 [36], resveratrol [37], and $\alpha$-lipoic acid [5, 38, 39]) have been used to improve mitochondrial function and fertility outcome. As aforementioned, the isolation of mitochondria from oocytes of young and healthy donors and transplantation into older and unhealthy oocytes may considerably benefit the rate of ATP production and oocyte quality in general. The mitochondrial transfer has been evaluated by some researchers in mouse, pig, hamster, cattle and human [26, 33, 40-42]. Investigators have suggested that mitochondrial transfer is an alternative treatment approach proposed for transferring healthy mtDNA to the next generation. Following mitochondrial transfer, the basal ATP required for aged-oocyte activation could be achieved during fertilization and blastocyst formation, and thereby contribute to subsequent embryonic development and an improved pregnancy outcome in women of advanced aging as well [12, 29, 43].

\section{Mitochondrial transfer procedures}

Unlike the nuclear genome received from both parents, mtDNA are transmitted exclusively maternally to the embryo in most mammalian species, and any mutations/ dysfunctions in maternal mtDNA reservoir could contribute to the most incurable genetic disorders, such as ophthalmoplegia disorders, Kearns-Sayre syndrome, maternally inherited Leigh syndrome, mitochondrial myopathy, Pearson syndrome, Coenzyme Q10 deficiency, mitochondrial DNA depletion syndromes (MDS), benign cytochrome $\mathrm{C}$ oxidase deficiency, chronic intestinal pseudo-obstruction (CIPO) etc. in offspring [44-46]. Hence, researchers tend to introduce different therapeutic approaches that involve microscopic manipulation by replacing aberrant mtDNA through mitochondria replacement procedures in the target oocytes to minimize mitochondria-related disorders in the offspring. Some of these techniques are described below.

\section{Pronuclear transfer (PNT)}

During transfer technique (Fig. 1), pronuclei are transferred from one zygote with abnormal mtDNA to another zygote with healthy mtDNA. First, both recipient and donor oocytes should be fertilized by the intended partner's sperm through intracytoplasmic sperm injection (ICSI) or IVF. Soon after the oocytes are fertilized and pronuclei is formed, the pronuclei from defective oocyte is transferred into the enucleated zygote using micromanipulation equipment. Therefore, the reconstructed zygote will have healthy mtDNA from the donor with original parents nuclear DNA [29, 47]. Results from various studies demonstrated that the use of PNT has a great potential to reduce the transmission of inadequate maternal mtDNA to the offspring. Craven et al. [47] showed that the carry-over of mtDNA after PNT was low (less than $2 \%$ ) or even non-detectable after cleavage and subsequent development until the blastocyst stage in vitro. This technique, however, is perhaps not 


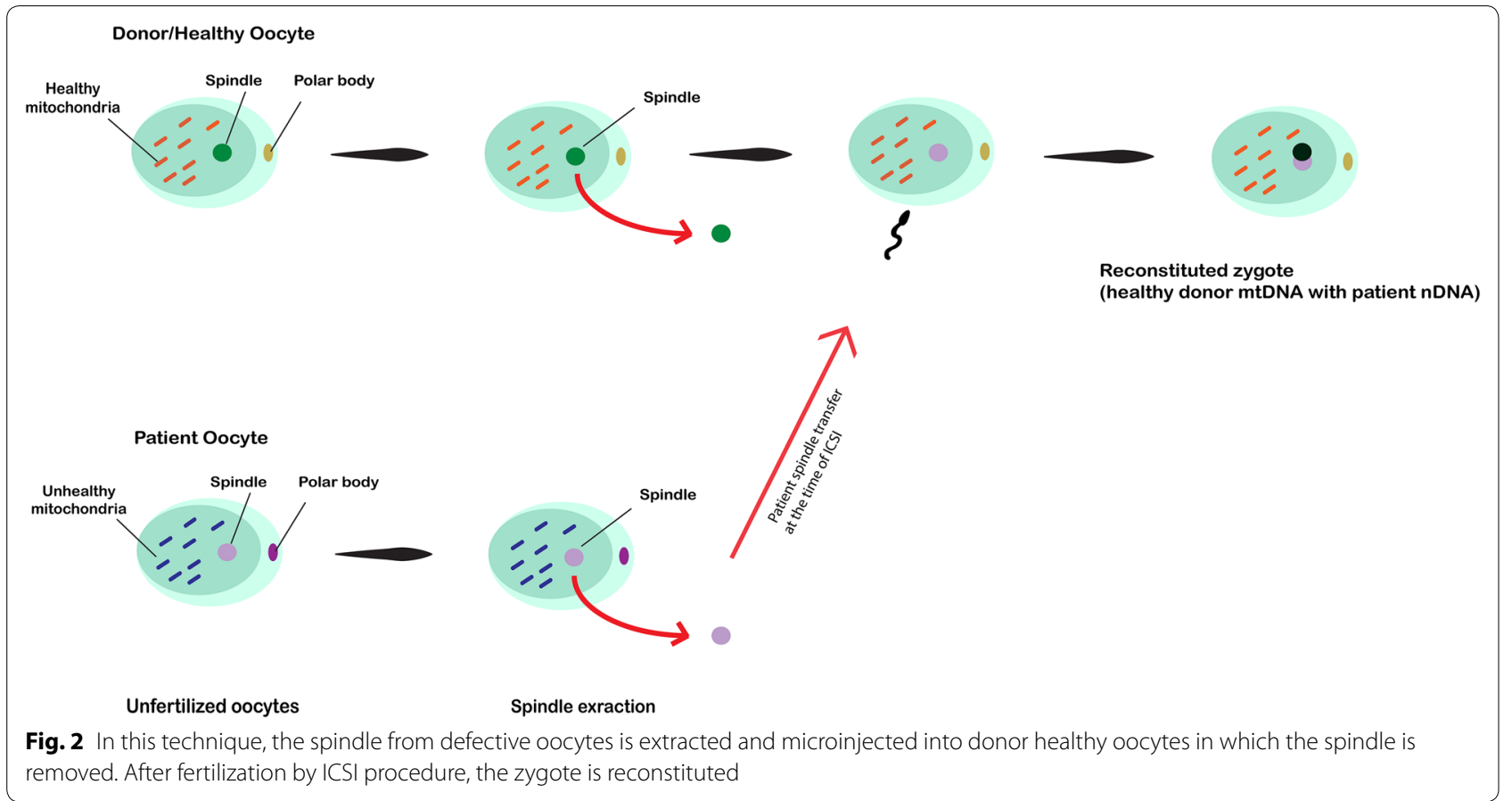

fully warranted for the prevention of mtDNA diseases carry-over and should be performed along with prenatal screening $[38,48]$.

\section{Spindle transfer}

This technique aims to provide healthy mitochondria from donor oocytes to deficient and/or aged counterparts; the metaphase II spindle was extracted from affected oocytes and transferred into donor healthy oocytes with a discarded spindle. After the fertilization by ICSI, the produced zygote cell contains mitochondria from the healthy donor and nuclear DNA from its original parent [29, 49] (Fig. 2). The first live birth case in human implementing spindle transfer was reported by Zhang et al. [46] in a 36-year-old woman diagnosed with Leigh syndrome with a history of abortion and mtDNA mutation rate of $24.5 \%$, in which a healthy boy in the 37th week of pregnancy was born after spindle transfer. Moreover, a study conducted by Tachibana et al. [50] showed live birth of three healthy offspring in non-human primate using spindle transfer technique by the genetic analysis. They successfully detected both donor oocyte nuclear DNA and original parent oocyte's mtDNA in the subsequent progeny. By using spindle transfer, it is estimated that mtDNA carryover to be less than $1 \%$ and has been introduced to minimize the transfer of congenital malformations of mtDNA to offspring $[48,51]$.

\section{Blastomere transfer}

This technique is performed following the fertilization of affected oocyte containing defective mitochondria through either IVF or ICSI and blastomere formation after cleavage. A blastomere is transplanted into the healthy donor oocyte that its spindle had already discarded. Eventually, the embryo is reconstituted after blastomere transfer (Fig. 3). No clinical studies have been carried out regarding the effectiveness of blastomere transfer in human; however, controversial studies using this method such as heteroplasmic babies are described in animal studies $[29,52]$.

\section{Ooplasmic or cytoplasmic transfer}

This method involves the simultaneous transfer of a fraction of the donor oocyte's cytoplasm containing healthy mitochondria along with sperm to the recipient oocyte's cytoplasm using ICSI procedure. In this case, the reconstituted zygote contains the original parent nuclear DNA and mixed mtDNA from both donor and recipient oocytes (Fig. 4). It is believed that the donated portion of ooplasm possesses healthy mitochondria and other beneficial cytosolic factors for promoting the development of oogenesis and embryogenesis [28, 53, 54]. However, this technique is not considered as a primary clinical technique due to the possibility of the heteroplasmy and chromosomal abnormalities in the subsequent embryos $[29,55]$. 

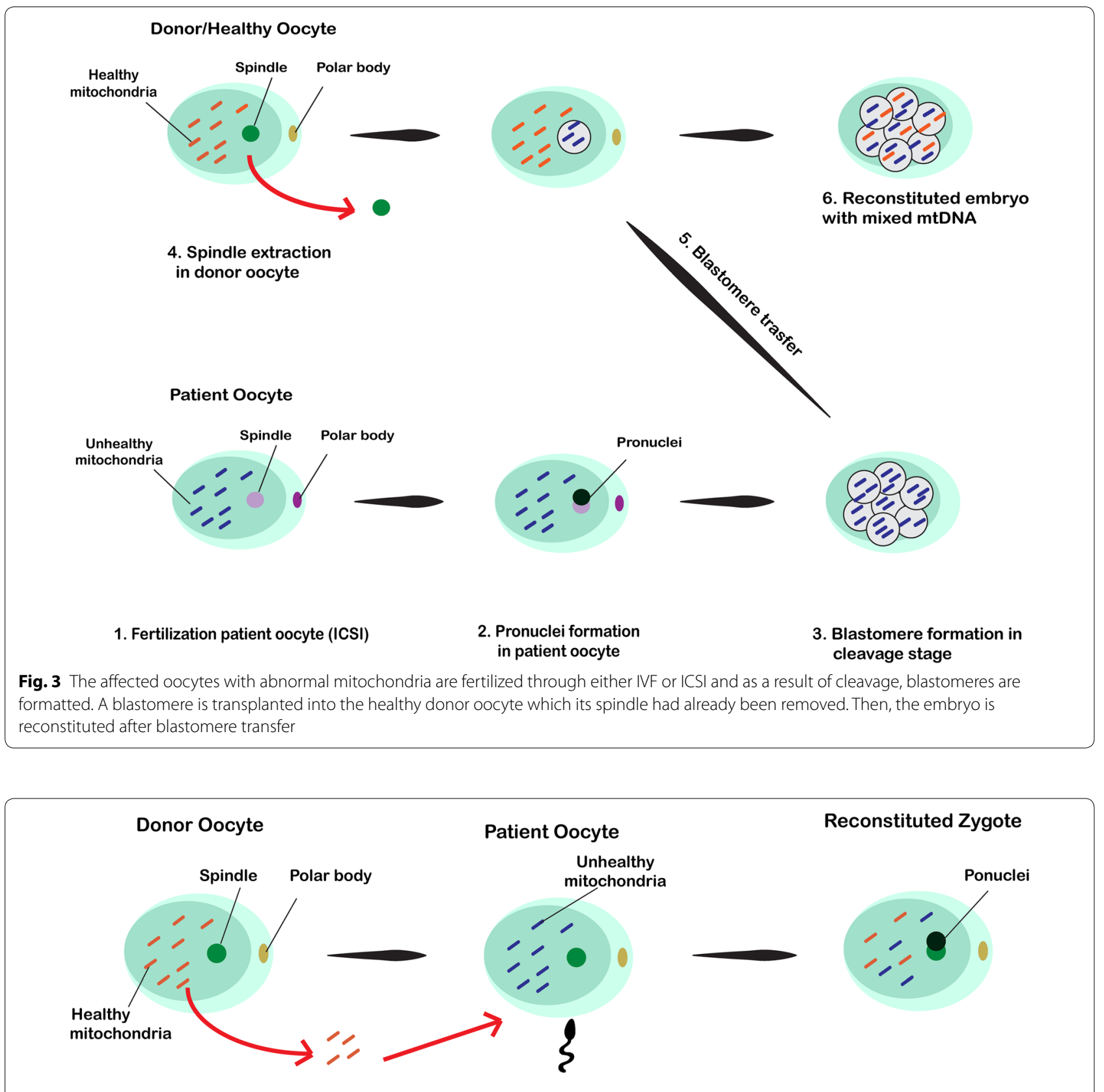

Healthy mitochondria

extraction

Mitochondrial transfer along with fertilization by ICSI with father sperm

Reconstituted Zygote

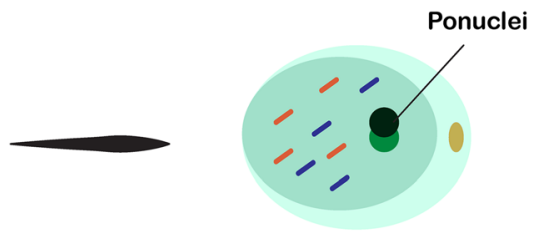

Fig. 4 In this procedure a fraction of the donor oocyte's cytoplasm containing healthy mitochondria is injected into the recipient oocyte's cytoplasm using ICSI procedure along with sperm. After cytoplasmic transfer, the reconstituted zygote contains parent nuclear DNA and mixed mtDNA from both donor and recipient oocytes

\section{Polar body transfer (PBT)}

In addition to previously described mitochondrial transfer techniques, polar body (PB) transfer is another method which has been investigated intensively. $\mathrm{PB}$ transfer has some advantages, such as minimal transfer of patient mtDNA to the intended embryos due to the lower content of mitochondria in the PB. Moreover, PBs can be easily observed and sampled by using a micro-pipette without damaging the chromosomes $[56,57]$.

$\mathrm{PB}$ transfer is performed in two subsequent procedures: Polar body 1 (PB1T) and polar body 2 (PB2T) transfer (Fig. 5). 


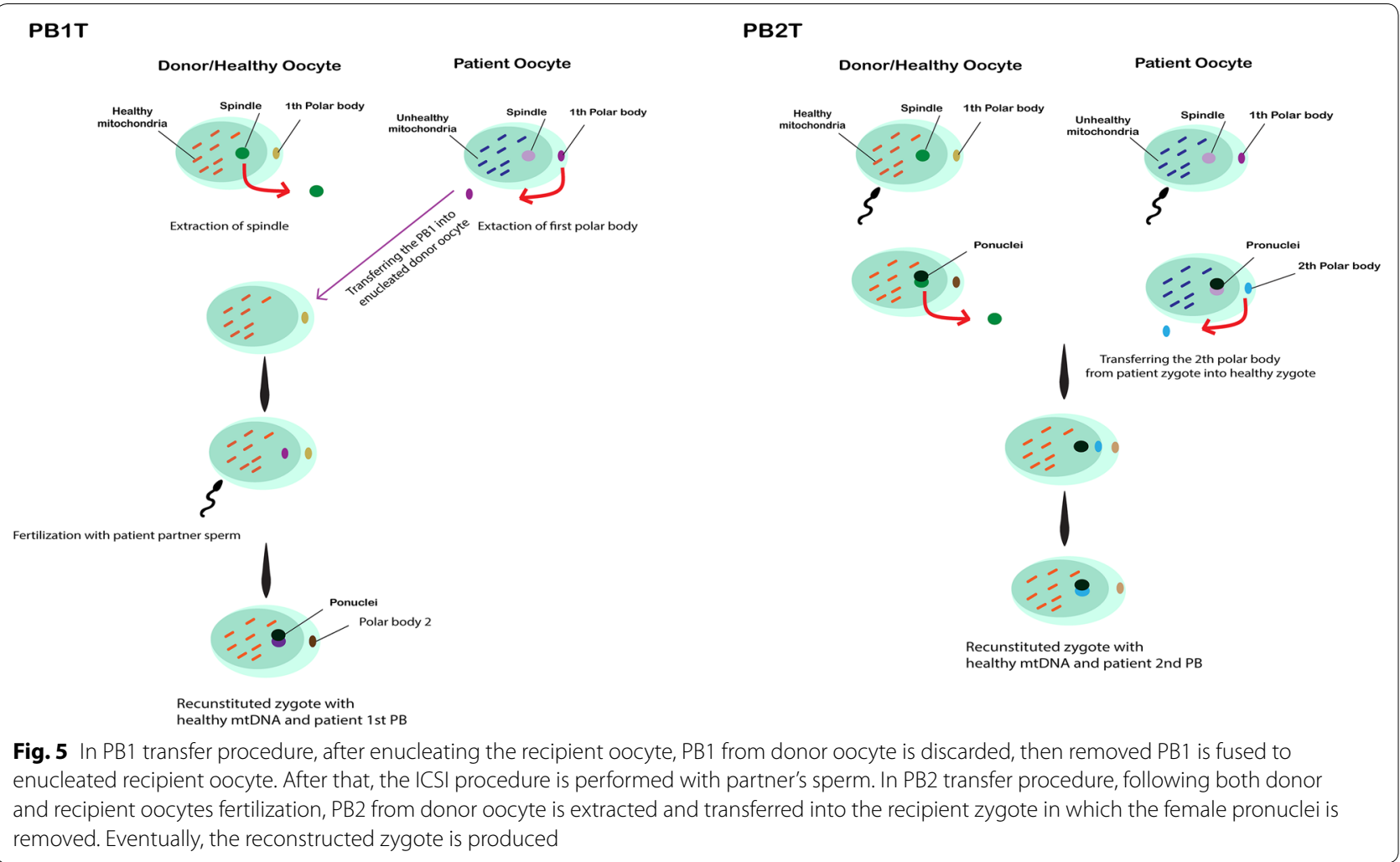

PB1T: after enucleating the recipient oocyte, PB1 is isolated from donor's mature MII oocyte. Extracted PB1 is fused to enucleated recipient oocyte. Then, ICSI procedure is performed with the intended partner's sperm which will result in reconstituted oocyte [57].

PB2T: following fertilization of both donor and recipient oocytes, second polar body from the original mother is extracted and injected into the recipient zygote in which the female pronuclei is removed. As a result, the reconstructed zygote is generated [57].

\section{AUGMENT technology}

Autologous germline mitochondrial energy transfer (AUGMENT) is the strategy launched by OvaScience in 2014 to transfer energy-producing mitochondria from autologous egg precursor cells into the eggs (Fig. 6). This method is implemented to enhance oocyte competence and increase the level of energy production required for oocyte maturation, normal embryonic development, and successful fertilization via providing the adequate quality, number, and function of mitochondria [21, 58, 59]. Based on reports of clinical studies in both human and animals, autologous mitochondria is injected cytoplasmically during the ICSI procedure through AUGMENT treatment.
This action has been shown to enhance the quality of the egg and fetus [17, 21, 58]. The mitochondrial population is extracted for AUGMENT treatment is known to be highly energetic with a minimum level of deletion and mutations and as these mitochondria are separated from patient's own cells. As a matter of fact, the probability of heteroplasmy in the offspring and presence of the third genetic material need scientific approval. It is noteworthy to mention that the introduction of exogenous materials and allogenic mitochondrial mass to the target oocytes must be evaluated regarding cellular immunity. Calling attention, some studies however showed that patients with multiple previous IVF failure might not be the good candidates for mitochondrial transplantation [17, 59-61].

\section{Results of clinical studies following mitochondrial transfer}

Most studies in animal and human setups have proved that ATP content and mtDNA copy numbers are relatively lower in aged oocytes when compared with young oocytes [43, 62, 63]. Simsek-Duran et al. [43] reported that the number of mitochondria declines in mouse and hamster oocytes during aging, and as a consequence, the ATP production falls to $35.4 \%$ and $38.4 \%$, respectively. Structural changes such as spherical to an elongated shape, vacuolization, cytoplasmic lamellae alterations, 

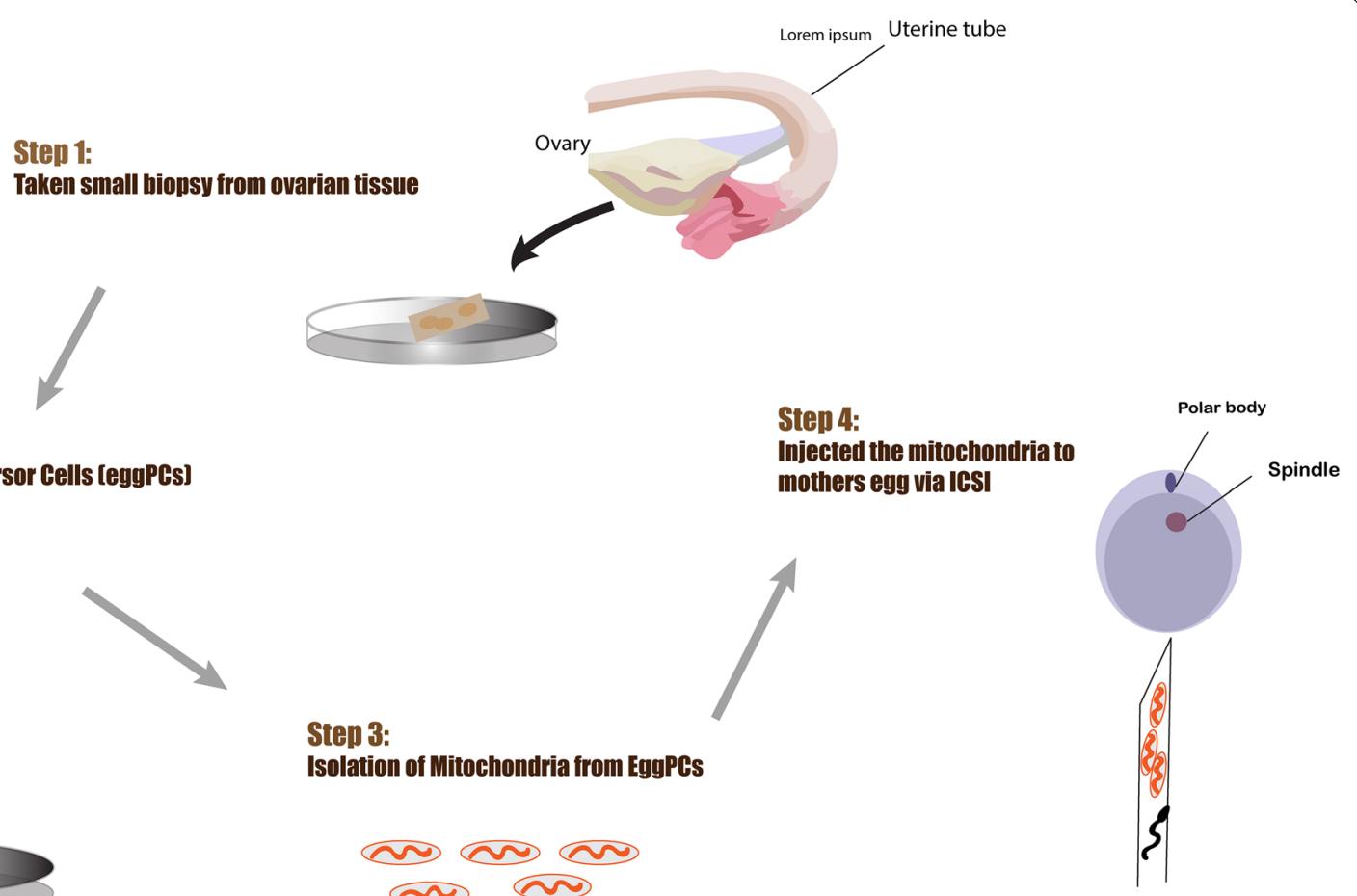

Step 2:

Isolation of Egg Precursor Cells [eggPCs] from ovarian tissue

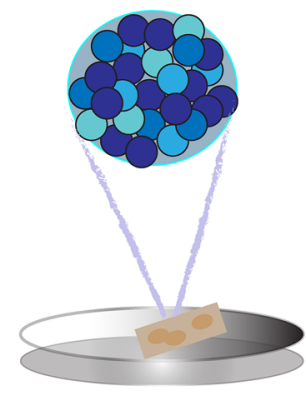

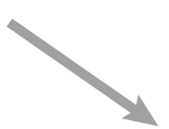

Step 3:

Isolation of Mitochondria from EggPCs

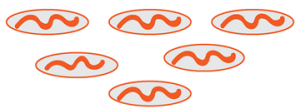

Step 4:

Injected the mitochondria to mothers egg via ICSI

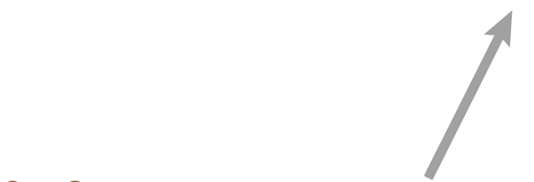

Fig. 6 In this procedure first, the biopsy is made from ovarian cortex and egg precursor cells (egg PCs) are isolated from biopsied ovarian tissue followed by mitochondria isolation. Eventually, the isolated autologous mitochondria are microinjected into affected oocytes through ICSI and cristae changes were also identified in the mitochondria during aging using transmission electron microscopy (TEM).

Li et al. [41] transplanted the autologous platelet mitochondria from young hamster into aged hamster oocytes with the aim of examining the biochemical and morphological changes of mitochondria in young and old hamster's oocytes and to increase oocyte quality after mitochondrial microinjection. The results indicated that ATP level and mtDNA copy number decreased by $21 \%$ and $56 \%$ respectively in elderly hamsters. Morphological changes and declined mitochondrial numbers were simultaneously observed in older oocytes in comparison with young hamster oocytes. An improved fertility rate was seen with increased blastocyst formation after IVF with autologous mitochondrial microinjection in aged oocytes. Li et al. suggested that platelets contain a low level of defective mitochondria due to high turnover rates (approximately 10 days) and could be considered as a good source of healthy mitochondria source compared to autologous granulosa cells in which their mtDNA mutations and deletions have been reported to increase during aging [16, 31, 62, 64]. In this respect, Kristensen et al. [12] have observed that oogonial stem cells (OSCs) are also not a suitable mitochondria source due to their low mitochondrial number as well as practical extraction difficulties.

Considering other cell sources for mitochondrial transfer, Tzeng et al. [65] injected the autologous cumulus granulosa cells (cGCs)-derived mitochondria into poor quality oocytes in patients with failed IVF/ICSI and evaluated the pregnancy outcome. The results revealed that the pregnancy rate in mitochondrial and non-mitochondrial transfer groups was $35.2 \%$ and $6.2 \%$, and the abortion rate was $15.4 \%$ and $100 \%$, respectively. On day 3 , embryo quality and fertilization rate were much better in mitochondrial transfer group compared to non-mitochondrial transfer group. Moreover, the DNA fragmentation and cellular apoptosis rates were decreased and twenty live births, including 7 twins and 2 ectopic pregnancies were confirmed after cGCs-derived mitochondrial transfer procedure. In another trial, Kong et al. [66] observed that co-injection of the autologous GCsderived mitochondria and sperm during ICSI in oocytes improved embryo quality and pregnancy rate (7 clinical pregnancy out of 18 cases in $>37$ years old women). However, fertilization rates were not statistically different between the control and treatment groups.

In line with the concept between aging and mitochondria quality, Fragouli et al. compared the mtDNA 
quantity in blastocysts and cleavage stage embryos between young and old patients. The results showed the high level of aneuploidy in blastocysts as well as low level of mtDNA content in cleavage stage embryos from older patients $[6,49]$. Poor quality oocytes have shown to contain low mtDNA copy number than good quality oocytes [33]. Hua et al. indicated that the morula, blastocyst, hatched blastocysts rates, and blastomere numbers in good quality oocytes (G-oocytes) and poor quality oocytes along with the mitochondria transfer (P-oocytes + MIT) are higher than poor quality oocytes (P-oocytes) without GCs-derived mitochondria transfer in bovine moldel while there is no difference between G-oocytes and P-oocytes + MIT. So, transferring mitochondria isolated from GCs of a similar breed of cattle could improve the quality of embryo during preimplantation development $[33,63]$. In another study conducted by Igarashi et al., they observed that mitochondrial membrane potential, oxygen consumption levels and mitochondrial transcriptional factor A (TFAM, a regulator of mitochondrial biogenesis) expression in young oocytes are higher in compared to aged oocytes. It has been reported that above-mentioned defects are associated with a decrease in ATP production, mitochondrial function, oocyte function, embryo development, viability, and ultimately poor pregnancy outcome [67-69]. Intriguingly, in another study by Igarashi et al., they did not observe any improvement in embryo development and fertilization rate in aged oocytes following the mitochondrial transfer. These authors attributed these findings to a possible defect in other important cytoplasmic organelles or factors within the oocyte, such as the endoplasmic reticulum and suggested that these organelles could also play a role in embryonic development [67]. In contrast to human study, Yi et al. injected the mice hepatocytes-derived mitochondria into the $2 \mathrm{PN}$ stage zygotes of young and older mice. The results showed that the development of the embryo to blastocyst stage has been remarkably improved in young mice (37.65\% versus $20.91 \%$ in injected and control groups, respectively). In older mice, $54.35 \%$ and $18.92 \%$ zygotes developed to morula stage and, $43.48 \%$ and $8.11 \%$ zygotes developed to the blastocyst stage in injected and control groups, respectively. These findings illustrated that the mitochondrial transfer at the zygote stage from older mice could significantly enhance the development to morula and blastocyst stages unlike human zygots [22, 63].

Since August 2015, two major fertility centers [FAKIH IVF (Dubai, United Arab Emirates) and the Toronto Center for Assisted Reproductive Technologies (TCART; Toronto, Canada)] have set up and developed AUGMENT as a therapeutic practice for women with poor reproductive performance. The data collected based on
93 patients following AUGMENT treatment from both centers showed that AUGMENT significantly increased pregnancy rates up to 3- to 6-fold in TCART and FAKIH IVF centers, respectively. Following 104 cycles of AUGMENT in these two centers, 4 live births from 6 babies were born which is comparable with 5 live births during 369 cycles of IVF without AUGMENT. Taken together, the results of these two centers demonstrated the clinical efficacy of mitochondrial transfer protocol for aged patients to improve human reproductive performance $[21,58]$. Recent studies have shown the existence of oogonial precursor cells (OPCs) in the human ovaries as one of the autologous sources of "healthy mitochondria". With this respect, Oktay et al. investigated the clinical effectiveness of injected OPCs-derived autologous mitochondria via ICSI in order to improve the quality of oocyte in women with multiple IVF failure. Following autologous mitochondrial injection (AMI), high fertilization rates and embryonic scores were observed which clearly reflects the improvement of oocyte quality. In this particular study, 10 women with the mean age of 34.7 were enrolled and subjected to mitochondrial transfer with remarkable improvement of fertilization rates (49.7 pre-AMI vs 78.3 post-AMI) and better embryo grades (2.3 pre-AMI vs 3.1 post-AMI) resulted in four clinical pregnancies was observed [25].

Barritt et al. [70] traced the transferred donor mitochondria following ooplasmic transfer in the blood samples of human babies by mtDNA fingerprinting and confocal microscopy after donor ooplasm staining. The results showed the distribution and replication of injected donor mitochondria after 24 and $48 \mathrm{~h}$ by the ooplasmic transplantation in preimplantation embryos. Also, the authors observed heteroplasmy in baby's blood. This paper was the first report in human germline genome modification resulting in healthy babies. Taken together, active and healthy mitochondria from healthy fertile donor oocytes were transplanted into the recipient patient oocytes during the ooplasmic transplantation technique resulted in approximately 30 live births worldwide.

Dale et al. [54] described the successful employment of oocyte cytoplasmic transfer to patients who suffered from idiopathic infertility due to a high level of embryonic fragmentation after IVF or ICSI. In this report, a fraction of oocyte cytoplasm of a 25-year-old woman was injected into oocytes of the patient during ICSI procedure after confirmation of normal metaphase-II maturation and morphology contributed a live birth of healthy twins. This result illustrates the successful application of cytoplasmic transfer for enhancing the oocyte and embryo quality. In a similar study conducted by Huang et al. [71], cytoplasm from donor's zygote and recipient 
Table 1 Summary of mitochondrial and/or ooplasmic transfer studies in the reproductive system

\begin{tabular}{|c|c|c|c|c|c|c|}
\hline Species & $\begin{array}{l}\text { Ooplasm or mitochondria } \\
\text { transfer }\end{array}$ & $\begin{array}{l}\text { Increased } \\
\text { fertilization } \\
\text { rate }\end{array}$ & $\begin{array}{l}\text { Embryo } \\
\text { development }\end{array}$ & $\begin{array}{l}\text { Improved } \\
\text { blastocysts } \\
\text { rate }\end{array}$ & Clinical pregnancy & References \\
\hline \multirow[t]{6}{*}{ Human } & Ooplasm & $\sqrt{ }$ & $\sqrt{ }$ & - & One baby & [53] \\
\hline & Ooplasm & $\sqrt{ }$ & $\sqrt{ }$ & $\sqrt{ }$ & 5 baby & {$[71]$} \\
\hline & Ooplasm & $\sqrt{ }$ & $\sqrt{ }$ & - & Twin & {$[73]$} \\
\hline & Oocyte mitochondria & $\sqrt{ }$ & $\sqrt{ }$ & $\sqrt{ }$ & - & {$[70]$} \\
\hline & Ooplasm & $\sqrt{ }$ & $\sqrt{ }$ & - & Twin & {$[54]$} \\
\hline & cGCs-mitochondria & $\sqrt{ }$ & $\sqrt{ }$ & $\sqrt{ }$ & 7 twins 2 ectopic pregnancies & {$[65]$} \\
\hline \multirow[t]{8}{*}{ Mouse } & Ooplasm & $\sqrt{ }$ & $\sqrt{ }$ & $\sqrt{ }$ & - & {$[79]$} \\
\hline & Mitochondria & $\sqrt{ }$ & $\sqrt{ }$ & $\sqrt{ }$ & - & {$[80]$} \\
\hline & Mitochondria & $\sqrt{ }$ & $\sqrt{ }$ & $\sqrt{ }$ & - & {$[26]$} \\
\hline & Somatic cyto/mito & - & $x$ & $\sqrt{ }$ & - & {$[81]$} \\
\hline & Hepatocytes mitochondria & $\sqrt{ }$ & $\sqrt{ }$ & $\sqrt{ }$ & - & {$[22]$} \\
\hline & ADSC-mitochondria & $\sqrt{ }$ & $\sqrt{ }$ & $\sqrt{ }$ & - & [8] \\
\hline & Ooplasm & $\sqrt{ }$ & $\sqrt{ }$ & $\sqrt{ }$ & $\sqrt{ }$ & [11] \\
\hline & Mitochondria & $\sqrt{ }$ & $\sqrt{ }$ & $\sqrt{ }$ & - & {$[82]$} \\
\hline \multirow[t]{2}{*}{ Cow } & Granulosa cells mitochondria & $\sqrt{ }$ & $\sqrt{ }$ & $\sqrt{ }$ & - & {$[33]$} \\
\hline & Ooplasm & $\sqrt{ }$ & $\sqrt{ }$ & $\sqrt{ }$ & - & {$[28]$} \\
\hline \multirow[t]{2}{*}{ Pig } & Mitochondria & $\sqrt{ }$ & $\sqrt{ }$ & $\sqrt{ }$ & - & {$[30]$} \\
\hline & Mitochondria & $\sqrt{ }$ & $\sqrt{ }$ & $\sqrt{ }$ & - & {$[40]$} \\
\hline Hamster & Platelet mitochondria & $\sqrt{ }$ & $\sqrt{ }$ & $\sqrt{ }$ & - & {$[41]$} \\
\hline Rabbit & Ooplasm & $x$ & $x$ & $x$ & $\times$ & {$[74]$} \\
\hline
\end{tabular}

husbands' sperms were injected simultaneously into the recipient's MII oocytes suffering from repeated implantation failure (RIF). Following injection MII oocytes developed to cleavage stage embryos and subsequently transferred to the patient's uterus. As a pregnancy outcome, five healthy babies from four normal pregnant recipients were born. This results confirmed the enhancement effect of zygote's cytoplasmic injection into oocytes upon ICSI, in patients with RIF. In an animal study, Chiaratti et al. demonstrated that ooplasmic transfer could rescue the exposed bovine oocytes to ethidium bromide (the mtDNA transcription and replication inhibitor), and promoted embryonic development and heteroplasmic calves birth [28, 72].

In another investigation, a 39-years-old woman with low ovarian reserve and ooplasmic deficiency (6.5 years of treatment history) were received ooplasm of a 27 -yearold woman during ICSI with successful fertilization and eventually a healthy baby girl was born in weight of $4356 \mathrm{~g}$ [53].

Lanzendorf et al. [73] reported a twin pregnancy in a 35 years old patient with a poor quality embryo history following a cytoplasmic transfer from cryopreserved donor oocytes into patient oocytes, however using this procedure in patients with advanced maternal aging ( $>40$ years of age) resulted in no positive pregnancies.
In an experiment conducted in animal setup, Wang et al. [8] microinjected the autologous mitochondria isolated from adipose-derived stem cells (ADSCs) from an aged mouse into its own GV oocytes. Examining the mtDNA copy numbers, spindle organization status and chromosomal alignment in MII oocytes in microinjection group revealed an enhancement in the maturation process and decline in aneuploidy rates compared to control group. They also concluded that autologous ADSCs-derived mitochondria microinjection via by ICSI procedure could improve the blastocyst rate (up to $30 \%$ vs. $15 \%$ ), embryogenesis and fertility outcome in aged mice.

In contrary to above-mentioned results, $\mathrm{Li}$ et al. [74] demonstrated that heterogeneous ooplasmic transfer to rabbit mature oocytes led to an apparent decline in development rate of blastocysts. However, the homogenous ooplasmic transfer did not impact on fertilization rate and embryonic development. They pointed out that the transmission of ooplasm into defective and low-quality oocytes could improve the fertilization rate and embryonic development, not oocytes with normal quality. The result of mitochondrial and/or ooplasmic transfer studies in the reproductive system is summarized in Table 1. 


\section{Ongoing clinical trials around the world about the AUGMENT technique}

To the best of our knowledge, trials and clinical application of mitochondrial transfer increasingly being performed for fertility and reproduction competence. In a study compiled by Ishii et al. [75], different authorities have been studied mitochondrial manipulation techniques in clinical setting. In this respect, different institutes from sixteen countries were selected to analyze the legal status of egg donation and genetic modification and discussed implications associated with implementation of current experimental approaches in reproductive medicine. The current clinical trials conducted in relation to AUGMENT treatment in women (ClinicalTrials. gov $^{1}$ ) are summarized in Table 2. The principal objective of these studies is to increase oocyte and embryo quality in patients or elder women with the history of IVF failure autologous microinjection of mitochondria from different sources. Data showed that mitochondrial source are either ovarian stem cells, GCs, and bone marrow mesenchymal stem cells in these clinical studies. The central consensus in these experimentations are the deterioration of oocyte mitochondrial function and reduced mitochondrial copy number as a major consequence of maternal aging which has significant negative effects on oocyte maturation and embryogenesis. Hence, the primary goal of these trials is to enrich the energy sources in affected oocytes via AUGMENT treatment.

\section{Ethical issues}

Numerous in vitro studies have been carried out on transferring the mitochondria between cells to promote the restoring process in affected target cells through intracellulary and extracellulary mechanisms in the various fields including reproduction. Because of some ethical concerns related to mitochondrial transfer procedures, such as the birth of a baby from a third parent, transmitting of the genetic disorders and the donation of mitochondria from other individuals, the mitochondrial transplantation has been considered controversial. Despite these limitations, the AUGMENT mitochondrial transfer has been introduced as an appropriate method for transferring healthy autologous mitochondria to circumvent the ethical issues and legal concerns. On the other hand, more randomized controlled clinical trials are demanded to further examine and validate the ethical and safety concerns $[59,61,76]$.

\footnotetext{
${ }^{1}$ ClinicalTrials.gov known as a database of general and private clinical studies that have been conducted around the world and a clinical studies source founded by the United States NLM (National Library of Medicine).
}

\section{Conclusion and future directions}

The association between ROS, aging, and metabolic abnormalities have been clearly illustrated 60 years ago [4]. In addition to factors related to aging, other factors correlated with poor quality oocytes such as overweight, polycystic ovary syndrome (PCOS), type II diabetes, and other environmental and genetical deficiencies have also been indicated. Oocytes of patients suffering from above-mentioned disorders contain a large number of mitochondrial malformations including structural and functional changes $[17,58,77]$. Due to the strong association between mitochondria and oocyte quality, subsequent embryonic development and fertility are likely to be affected directly by the quality of the mitochondria and mtDNA. Therefore, impairment in mitochondrial function and oocyte mitochondrial deficiency may have a negative effect on reproduction and fertility, hence increasing mitochondrial numbers and/or improving mitochondrial function through mitochondrial transfer from high-quality oocyte to low-quality oocyte could lead to improved fertility outcome and benefit female patients suffering from diabetes, recurrent IVF failure and repeated pregnancy failure associated with aging.

It has been proposed that the injection a small fraction of donor's oocyte cytoplasm containing healthy mitochondria may restore the normal function of oocytes [71]. In the past, the transfer of donor oocyte cytoplasm resulted in some live births; however, considering heteroplasmic concerns nowadays, this technique is less recommended. To further confirm the safety of the procedure, optimal protocols, including maintenance of homoplasmy in the offspring through using of approved sources of mitochondria (donor mitochondria) without deletions or mutations in mtDNA, or implementation of ovarian origin egg-precursor cells should be established and considered $[25,32,78]$. OvaScience has reported that egg precursor cells (EPCs)-derived mitochondria from germline and unipotent cells in the outer ovarian cortex are the most potential and high-quality sources of healthy and active mitochondria to be used in AUGMENT technique. Therefore, the evaluation of healthy and active mitochondria prior to oocyte reconstruction procedures can be helpful for the selection of fertilizable oocytes [30]. As mitochondria are vital for oocyte maturation and embryo development, mitochondria assessment and application of appropriate technique for mitochondria injection into the defective oocyte are urgently needed especially in women at the risk of disorders associated with aging. 


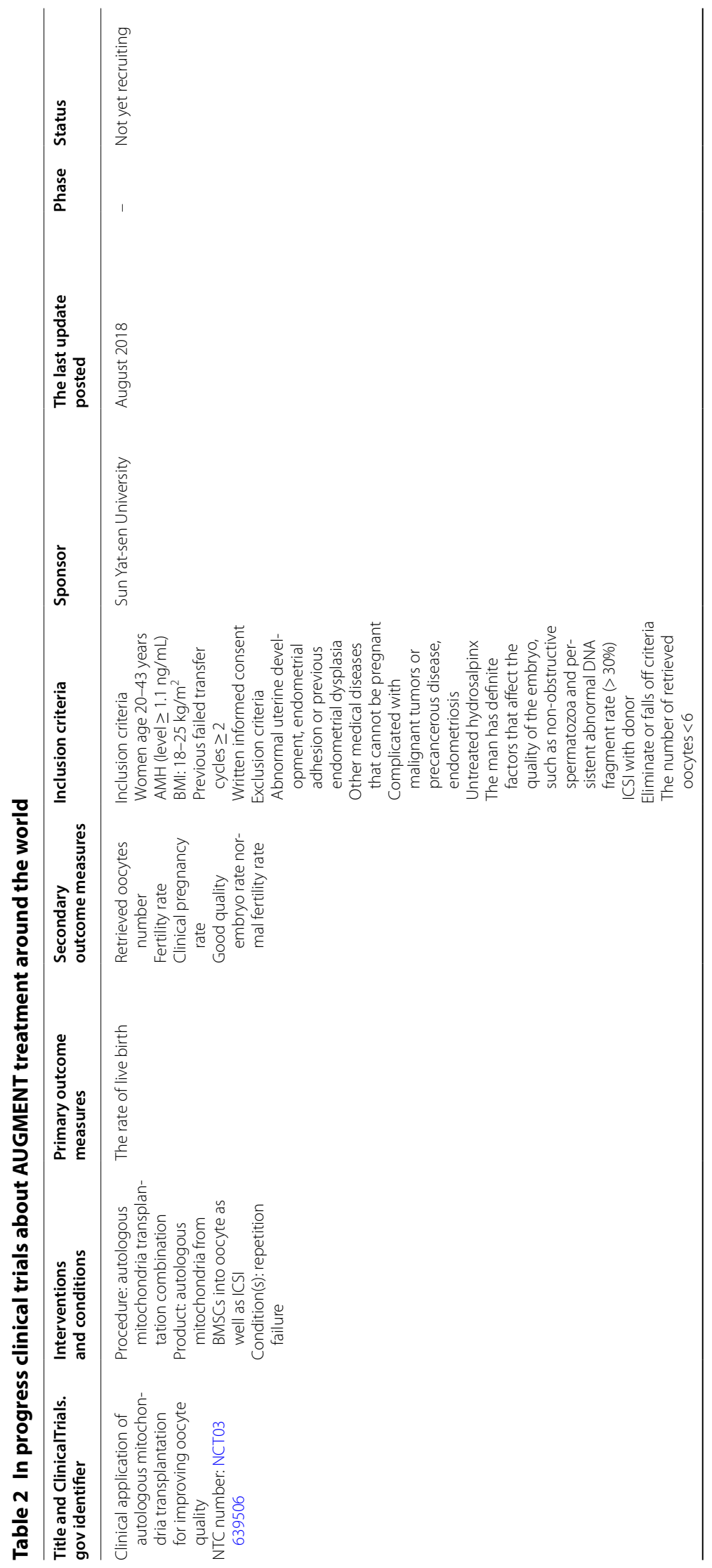




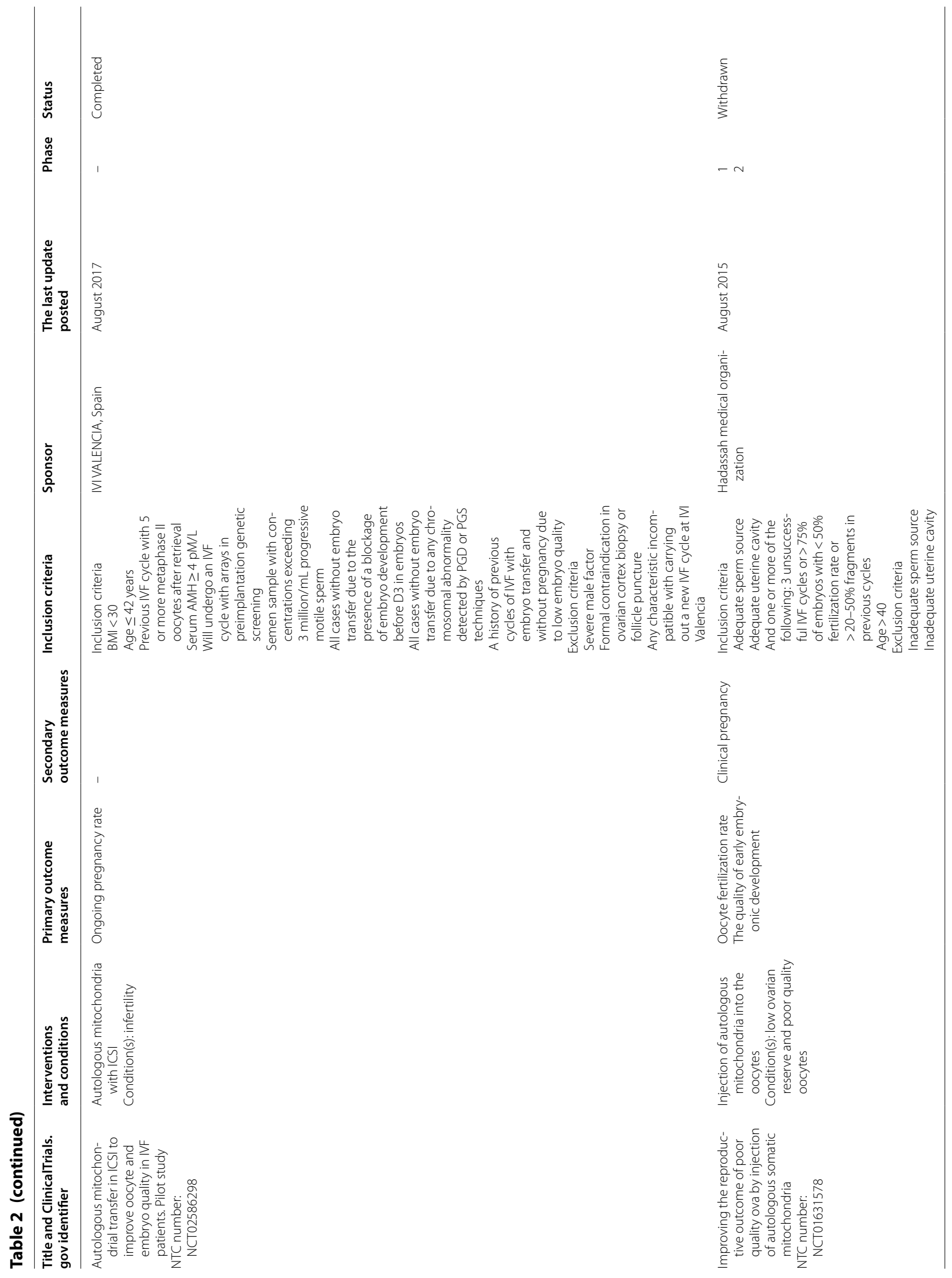




\section{Abbreviations}

MFRTA: mitochondrial free radical theory of aging; ROS: reactive oxygen species; MtDNA: mitochondrial DNA; PGCs: primordial germ cells; CIPO: chronic intestinal pseudo-obstruction; MDS: mitochondrial DNA depletion syndromes; PNT: pronuclear transfer; ICSI: intracytoplasmic sperm injection; IVF: in vitro fertilization; PBT: polar body transfer; AUGMENT: autologous germline mitochondrial energy transfer; OSCs: oogonial stem cells; CGCs: cumulus granulosa cells; AMI: autologous mitochondrial injection; ADSC: adipose tissue-derived stem cells; EPCs: egg precursor cells.

\section{Acknowledgements}

This study was supported by a grant (Grant No. 59253) from Tabriz University of Medical Sciences. Authors wish to thank the personnel of Stem Cell research Center for guidance and help.

\section{Authors' contributions}

MM designed and directed the writing of the paper. HM and MM wrote the manuscript in consultation with PSJT, RR, and AR. MN and MH reviewed and commented on the manuscript. HM and MM designed the figures and tables. All authors read and approved the final manuscript.

\section{Funding}

Not applicable.

\section{Availability of data and materials}

Not applicable.

\section{Ethics approval and consent to participate}

Not applicable.

\section{Consent for publication}

Not applicable.

\section{Competing interests}

The authors declare that they have no competing interests.

\section{Author details}

${ }^{1}$ Women's Reproductive Health Research Center, Tabriz University of Medical Sciences, Tabriz, Iran. ${ }^{2}$ Department of Clinical Sciences, Faculty of Veterinary Medicine, Ferdowsi University of Mashhad, Mashhad, Iran. ${ }^{3}$ Center for Developmental Biology and Regenerative Medicine Research, National Taiwan University/NTU, Taipei, Taiwan. ${ }^{4}$ Department of Veterinary Medicine, School of Veterinary Medicine, National Taiwan University/NTU, Taipei, Taiwan. ${ }^{5}$ Aging Research Institute, Tabriz University of Medical Sciences, Tabriz, Iran.

${ }^{6}$ Stem Cell Research Center, Tabriz University of Medical Sciences, Tabriz, Iran. ${ }^{7}$ Department of Applied Cell Sciences, Faculty of Advanced Medical Sciences, Tabriz University of Medical Sciences, Tabriz, Iran. ${ }^{8}$ Department of Reproductive Biology, Faculty of Advanced Medical Sciences, Tabriz University of Medical Sciences, Tabriz, Iran.

Received: 25 July 2019 Accepted: 21 November 2019 Published online: 29 November 2019

\section{References}

1. Barja G. Chapter one-The mitochondrial free radical theory of aging. In: Osiewacz HD, editor. Progress in molecular biology and translational science, vol. 127. Waltham: Academic Press; 2014. p. 1-27.

2. Kirkwood TB. Evolution of ageing. Mech Ageing Dev. 2002;123(7):737-45.

3. Kirkwood TB. A systematic look at an old problem. Nature. 2008:451(7179):644-7.

4. Harman D. Free radical theory of aging. Mutat Res/DNAging. 1992;275(3):257-66.

5. Taylor RW, Turnbull DM. Mitochondrial DNA mutations in human disease. Nat Rev Genet. 2005:6(5):389-402.

6. Fragouli E, Spath K, Alfarawati S, Kaper F, Craig A, Michel CE, et al. Altered levels of mitochondrial DNA are associated with female age, aneuploidy, and provide an independent measure of embryonic implantation potential. PLoS Genet. 2015:11(6):e1005241.
7. Green DR, Kroemer G. The pathophysiology of mitochondrial cell death. Science. 2004;305(5684):626-9.

8. Wang ZB, Hao JX, Meng TG, Guo L, Dong MZ, Fan LH, et al. Transfer of autologous mitochondria from adipose tissue-derived stem cells rescues oocyte quality and infertility in aged mice. Aging. 2017;9(12):2480-8.

9. Bratic I, Trifunovic A. Mitochondrial energy metabolism and ageing. Biochim Biophys Acta. 2010;1797(6-7):961-7.

10. Contreras L, Drago I, Zampese E, Pozzan T. Mitochondria: the calcium connection. Biochim Biophys Acta. 2010;1797(6-7):607-18.

11. Cheng Y, Wang K, Kellam LD, Lee YS, Liang CG, Han Z, et al. Effects of ooplasm manipulation on DNA methylation and growth of progeny in mice. Biol Reprod. 2009;80(3):464-72.

12. Kristensen SG, Pors SE, Andersen CY. Improving oocyte quality by transfer of autologous mitochondria from fully grown oocytes. Hum Reprod. 2017;32(4):725-32.

13. Anderson S, Bankier AT, Barrell BG, de Bruijn MHL, Coulson AR, Drouin J, et al. Sequence and organization of the human mitochondrial genome. Nature. 1981:290(5806):457-65.

14. Gadaleta MN, Rainaldi G, Lezza AM, Milella F, Fracasso F, Cantatore P. Mitochondrial DNA copy number and mitochondrial DNA deletion in adult and senescent rats. Mutat Res. 1992;275(3-6):181-93.

15. Mecocci P, Fano G, Fulle S, MacGarvey U, Shinobu L, Polidori MC, et al. Age-dependent increases in oxidative damage to DNA, lipids, and proteins in human skeletal muscle. Free Radic BiolMed. 1999;26(3-4):303-8.

16. Bentov Y, Yavorska T, Esfandiari N, Jurisicova A, Casper RF. The contribution of mitochondrial function to reproductive aging. J Assist Reprod Genet. 2011;28(9):773-83.

17. Babayev E, Seli E. Oocyte mitochondrial function and reproduction. Curr Opin Obstet Gynecol. 2015;27(3):175-81.

18. Song WH, Ballard JW, Yi YJ, Sutovsky P. Regulation of mitochondrial genome inheritance by autophagy and ubiquitin-proteasome system: implications for health, fitness, and fertility. Biomed Res Int. 2014;2014:981867.

19. Keogh M, Chinnery PF. Hereditary mtDNA heteroplasmy: a baseline for aging? Cell Metab. 2013;18(4):463-4.

20. Ross JM, Stewart JB, Hagstrom E, Brene S, Mourier A, Coppotelli G, et al. Germline mitochondrial DNA mutations aggravate ageing and can impair brain development. Nature. 2013:501(7467):412-5.

21. Woods DC, Tilly JL. Autologous germline mitochondrial energy transfer (AUGMENT) in human assisted reproduction. Semin Reprod Med. 2015;33(6):410-21.

22. YiYC, Chen MJ, Ho JY, Guu HF, Ho ES. Mitochondria transfer can enhance the murine embryo development. J Assist Reprod Genet. 2007:24(10):445-9.

23. Mobarak H, Heidarpour M, Lolicato F, Nouri M, Rahbarghazi R, Mahdipour M. Physiological impact of extracellular vesicles on female reproductive system; highlights to possible restorative effects on female age-related fertility. BioFactors. 2019;45(3):293-303.

24. Torner H, Brussow KP, Alm H, Ratky J, Pohland R, Tuchscherer A, et al. Mitochondrial aggregation patterns and activity in porcine oocytes and apoptosis in surrounding cumulus cells depends on the stage of preovulatory maturation. Theriogenology. 2004;61(9):1675-89.

25. Oktay K, Baltaci V, Sonmezer M, Turan V, Unsal E, Baltaci A, et al. Oogonial precursor cell-derived autologous mitochondria injection to improve outcomes in women with multiple IVF failures due to low oocyte quality: a clinical translation. Reprod Sci. 2015;22(12):1612-7.

26. Van Blerkom J, Sinclair J, Davis P. Mitochondrial transfer between oocytes: potential applications of mitochondrial donation and the issue of heteroplasmy. Hum Reprod. 1998;13(10):2857-68.

27. May-Panloup P, Boucret L, Chao de la Barca J-M, Desquiret-Dumas $\checkmark$, Ferré-L'Hotellier $V$, Morinière $C$, et al. Ovarian ageing: the role of mitochondria in oocytes and follicles. Human Reprod Update. 2016;22(6):725-43.

28. Chiaratti MR, Bressan FF, Ferreira CR, Caetano AR, Smith LC, Vercesi AE, et al. Embryo mitochondrial DNA depletion is reversed during early embryogenesis in cattle. Biol Reprod. 2010;82(1):76-85.

29. Reznichenko AS, Huyser C, Pepper MS. Mitochondrial transfer: implications for assisted reproductive technologies. Appl Transl Genom. 2016;11:40-7. 
30. El Shourbagy SH, Spikings EC, Freitas M, St John JC. Mitochondria directly influence fertilisation outcome in the pig. Reproduction. 2006;131(2):233-45.

31. Van Blerkom J. Mitochondrial function in the human oocyte and embryo and their role in developmental competence. Mitochondrion. 2011;11(5):797-813.

32. Chappel S. The role of mitochondria from mature oocyte to viable blastocyst. Obstet Gynecol Int. 2013;2013:183024.

33. Hua S, Zhang Y, Li XC, Ma LB, Cao JW, Dai JP, et al. Effects of granulosa cell mitochondria transfer on the early development of bovine embryos in vitro. Cloning Stem Cells. 2007;9(2):237-46.

34. Sathananthan AH, Trounson AO. Mitochondrial morphology during preimplantational human embryogenesis. Hum Reprod. 2000;15(Suppl 2):148-59.

35. Moawad AR, Taketo T, Tan SL, Xu B. L-Carnitine supplementation during vitrification of mouse germinal vesicle stage-oocytes and their subsequent in vitro maturation improves meiotic spindle configuration and mitochondrial distribution in metaphase II oocytes. Hum Reprod. 2014;29(10):2256-68.

36. Bentov $Y$, Hannam T, Jurisicova A, Esfandiari N, Casper RF. Coenzyme Q10 supplementation and oocyte aneuploidy in women undergoing IVF-ICSI treatment. Clin Med Insights Reprod Health. 2014;8:31-6.

37. Lagouge M, Argmann C, Gerhart-Hines Z, Meziane H, Lerin C, Daussin $F$, et al. Resveratrol improves mitochondrial function and protects against metabolic disease by activating SIRT1 and PGC-1alpha. Cell. 2006;127(6):1109-22

38. Sato A, Kono T, Nakada K, Ishikawa K, Inoue S, Yonekawa H, et al. Gene therapy for progeny of mito-mice carrying pathogenic mtDNA by nuclear transplantation. Proc Natl Acad Sci USA. 2005;102(46):16765-70.

39. Yi X, Maeda N. Endogenous production of lipoic acid is essential for mouse development. Mol Cell Biol. 2005;25(18):8387-92.

40. Cagnone GL, Tsai TS, Makanji Y, Matthews P, Gould J, Bonkowski MS, et al. Restoration of normal embryogenesis by mitochondrial supplementation in pig oocytes exhibiting mitochondrial DNA deficiency. Sci Rep. 2016;6:23229.

41. Li F, Ford WE, Duran FS, Castora FJ, Jones HW, Swanson JR. Mitochondrial changes in aged oocytes and improvement of fertility rate through autologous platelets mitochondrial microinjection. Fertil Steril. 2010;94(4):S57.

42. St. John JC, Makanji Y, Johnson JL, Tsai T-S, Lagondar S, Rodda F, et al. The transgenerational effects of oocyte mitochondrial supplementation. Sci Rep. 2019;9(1):6694

43. Simsek-Duran F, Li F, Ford W, Swanson RJ, Jones HW Jr, Castora FJ. Ageassociated metabolic and morphologic changes in mitochondria of individual mouse and hamster oocytes. PLoS ONE. 2013;8(5):e64955.

44. Brunstein J. Molecular diagnosis: mitochondrial genetic disorders; 2015. https://www.mlo-online.com/mitochondrial-genetic-disorders.php.

45. Falk MJ, Sondheimer N. Mitochondrial genetic diseases. Curr Opin Pediatr. 2010;22(6):711-6.

46. Zhang J, Liu H, Luo S, Chavez-Badiola A, Liu Z, Yang M, et al. First live birth using human oocytes reconstituted by spindle nuclear transfer for mitochondrial DNA mutation causing Leigh syndrome. Fertil Steril. 2016;106(3):e375-6.

47. Craven L, Tuppen HA, Greggains GD, Harbottle SJ, Murphy JL, Cree LM, et al. Pronuclear transfer in human embryos to prevent transmission of mitochondrial DNA disease. Nature. 2010;465(7294):82-5.

48. Craven L, Tang MX, Gorman GS, De Sutter P, Heindryckx B. Novel reproductive technologies to prevent mitochondrial disease. Hum Reprod Update. 2017;23(5):501-19.

49. Tanaka A, Watanabe S. Can cytoplasmic donation rescue aged oocytes? Reprod Med Biol. 2019;18(2):128-39.

50. Tachibana M, Sparman M, Sritanaudomchai H, Ma H, Clepper L, Woodward J, et al. Mitochondrial gene replacement in primate offspring and embryonic stem cells. Nature. 2009;461(7262):367-72.

51. Paull D, Emmanuele V, Weiss KA, Treff N, Stewart L, Hua H, et al. Nuclear genome transfer in human oocytes eliminates mitochondrial DNA variants. Nature. 2013;493(7434):632-7.

52. Ferreira CR, Meirelles FV, Yamazaki W, Chiaratti MR, Meo SC, Perecin F, et al. The kinetics of donor cell mtDNA in embryonic and somatic donor cellderived bovine embryos. Cloning Stem Cells. 2007;9(4):618-29.
53. Cohen J, Scott R, Schimmel T, Levron J, Willadsen S. Birth of infant after transfer of anucleate donor oocyte cytoplasm into recipient eggs. Lancet. 1997:350(9072):186-7.

54. Dale B, Wilding M, Botta G, Rasile M, Marino M, Di Matteo L, et al. Pregnancy after cytoplasmic transfer in a couple suffering from idiopathic infertility: case report. Hum Reprod. 2001;16(7):1469-72.

55. Brenner CA, Barritt JA, Willadsen S, Cohen J. Mitochondrial DNA heteroplasmy after human ooplasmic transplantation. Fertil Steril. 2000;74(3):573-8.

56. Wang T, Sha H, Ji D, Zhang HL, Chen D, Cao Y, et al. Polar body genome transfer for preventing the transmission of inherited mitochondrial diseases. Cell. 2014;157(7):1591-604

57. Zhang SP, Lu CF, Gong F, Xie PY, Hu L, Zhang SJ, et al. Polar body transfer restores the developmental potential of oocytes to blastocyst stage in a case of repeated embryo fragmentation. J Assist Reprod Genet. 2017;34(5):563-71.

58. Fakih MH. The AUGMENTSM treatment: physician reported outcomes of the initial global patient experience. J Fertil In Vitro IVF Worldw Reprod Med Genet Stem Cell Biol. 2015. https://doi.org/10.4172/23754508.1000154.

59. Cozzolino M, Marin D, Sisti G. New frontiers in IVF: mtDNA and autologous germline mitochondrial energy transfer. Reprod Biol Endocrinol. 2019;17(1):55.

60. Labarta E, de Los Santos MJ, Herraiz S, Escriba MJ, Marzal A, Buigues A, et al. Autologous mitochondrial transfer as a complementary technique to intracytoplasmic sperm injection to improve embryo quality in patients undergoing in vitro fertilization-a randomized pilot study. Fertil Steril. 2019;111(1):86-96.

61. McCully JD, Levitsky S, del Nido PJ, Cowan DB. Mitochondrial transplantation for therapeutic use. Clin Transl Med. 2016;5(1):16.

62. I wata H, Goto H, Tanaka H, Sakaguchi Y, Kimura K, Kuwayama T, et al. Effect of maternal age on mitochondrial DNA copy number, ATP content and IVF outcome of bovine oocytes. Reprod Fertil Dev. 2011;23(3):424-32.

63. Zeng HT, Ren Z, Yeung WS, Shu YM, Xu YW, Zhuang GL, et al. Low mitochondrial DNA and ATP contents contribute to the absence of birefringent spindle imaged with PolScope in in vitro matured human oocytes. Hum Reprod. 2007;22(6):1681-6.

64. Li F. Age-related hamster mitochondrial changes and oocyte changes following autologous platelet mitochondrial microinjection [Dissertation]. ProQuest Dissertations Publishing: Old Dominion University; 2011.

65. Tzeng CR, Hsieh RH, Au HK, Yen YH, Chang SJ, Cheng YF. Mitochondria transfer (MIT) into oocyte from autologous cumulus granulosa cells (cGCS). Fertil Steril. 2004;82:S53.

66. Kong LH, Liu Z, Li H, Zhu L, Chen SM, Chen SL, et al. Mitochondria transfer from self-granular cells to improve embryos' quality. Zhonghua fu chan ke za zhi. 2004:39(2):105-7.

67. Igarashi H, Takahashi T, Abe H, Nakano H, Nakajima O, Nagase S. Poor embryo development in post-ovulatory in vivo-aged mouse oocytes is associated with mitochondrial dysfunction, but mitochondrial transfer from somatic cells is not sufficient for rejuvenation. Hum Reprod. 2016;31(10):2331-8

68. Thundathil J, Filion F, Smith LC. Molecular control of mitochondrial function in preimplantation mouse embryos. Mol Reprod Dev. 2005;71(4):405-13.

69. Larsson NG, Wang J, Wilhelmsson $\mathrm{H}$, Oldfors A, Rustin P, Lewandoski M, et al. Mitochondrial transcription factor $A$ is necessary for mtDNA maintenance and embryogenesis in mice. Nat Genet. 1998;18(3):231-6.

70. Barritt JA, Brenner CA, Malter HE, Cohen J. Mitochondria in human offspring derived from ooplasmic transplantation. Hum Reprod. 2001;16(3):513-6.

71. Huang CC, Cheng TC, Chang HH, Chang CC, Chen Cl, Liu J, et al. Birth after the injection of sperm and the cytoplasm of tripronucleate zygotes into metaphase II oocytes in patients with repeated implantation failure after assisted fertilization procedures. Fertil Steril. 1999;72(4):702-6.

72. Ferreira CR, Burgstaller JP, Perecin F, Garcia JM, Chiaratti MR, Meo SC, et al. Pronounced segregation of donor mitochondria introduced by bovine ooplasmic transfer to the female germ-line. Biol Reprod. 2010;82(3):563-71.

73. Lanzendorf SE, Mayer JF, Toner J, Oehninger S, Saffan DS, Muasher S. Pregnancy following transfer of ooplasm from cryopreserved-thawed donor oocytes into recipient oocytes. Fertil Steril. 1999;71(3):575-7. 
74. Li J, Song Y, Li H, Zhang J. Cytoplasm transfer in mature rabbit oocytes. Electron J Biol. 2005;1 (1):6-8.

75. Ishii T, Hibino Y. Mitochondrial manipulation in fertility clinics: regulation and responsibility. Reprod Biomed Soc Online. 2018;5:93-109.

76. Caicedo A, Aponte PM, Cabrera F, Hidalgo C, Khoury M. Artificial mitochondria transfer: current challenges, advances, and future applications. Stem Cells Int. 2017:2017:23.

77. Niu Z, Lin N, Gu R, Sun Y, Feng Y. Associations between insulin resistance, free fatty acids, and oocyte quality in polycystic ovary syndrome during in vitro fertilization. J Clin Endocrinol Metab. 2014;99(11):E2269-76.

78. Schatten H, Sun Q-Y, Prather R. The impact of mitochondrial function/ dysfunction on IVF and new treatment possibilities for infertility. Reprod Biol Endocrinol. 2014;12(1):111.

79. Levron J, Willadsen S, Bertoli M, Cohen J. The development of mouse zygotes after fusion with synchronous and asynchronous cytoplasm. Hum Reprod. 1996;11(6):1287-92.
80. Pinkert CA, Irwin $\mathrm{MH}$, Johnson LW, Moffatt RJ. Mitochondria transfer into mouse ova by microinjection. Transgenic Res. 1997;6(6):379-83.

81. Takeda K, Tasai M, Akagi S, Matsukawa K, Takahashi S, Iwamoto M, et al. Microinjection of serum-starved mitochondria derived from somatic cells affects parthenogenetic development of bovine and murine oocytes. Mitochondrion. 2010;10(2):137-42.

82. Ebert KM, Alcivar A, Liem H, Goggins R, Hecht NB. Mouse zygotes injected with mitochondria develop normally but the exogenous mitochondria are not detectable in the progeny. Mol Reprod Dev. 1989;1(3):156-63.

\section{Publisher's Note}

Springer Nature remains neutral with regard to jurisdictional claims in published maps and institutional affiliations.
Ready to submit your research? Choose BMC and benefit from:

- fast, convenient online submission

- thorough peer review by experienced researchers in your field

- rapid publication on acceptance

- support for research data, including large and complex data types

- gold Open Access which fosters wider collaboration and increased citations

- maximum visibility for your research: over $100 \mathrm{M}$ website views per year

At BMC, research is always in progress.

Learn more biomedcentral.com/submissions 